Citation: Ginak E. (2021) The «D.I. Mendeleev's Periodic System of the Elements» Mural Near the Mendeleev Institute for Metrology in Saint Petersburg: How Metrologists Celebrated the 100th Anniversary of the Scientist. Substantia 5(2): 79-84. doi: 10.36253/ Substantia-1028

Received: Jul 23, 2020

Revised: Jun 17, 2021

Just Accepted Online: Jun 17, 2021

Published: Sep 10, 2021

Copyright: (c) 2021 Ginak E. This is an open access, peer-reviewed article published by Firenze University Press (http://www.fupress.com/substantia) and distributed under the terms of the Creative Commons Attribution License, which permits unrestricted use, distribution, and reproduction in any medium, provided the original author and source are credited.

Data Availability Statement: All relevant data are within the paper and its Supporting Information files.

Competing Interests: The Author(s) declare(s) no conflict of interest.

Research Articles

\title{
The «D.I. Mendeleev's Periodic System of the Elements» Mural Near the Mendeleev Institute for Metrology in Saint Petersburg: How Metrologists Celebrated the $\mathbf{1 0 0}^{\text {th }}$ Anniversary of the Scientist
}

\author{
ELENA GINAK \\ D.I. Mendeleyev Institute for Metrology (VNIIM), St. Petersburg, Russia \\ E-mail: ginak@vniim.ru
}

\begin{abstract}
This article is timed to the celebration of the International Year of the Periodic Table of Chemical Elements, declared by the UN and UNESCO in connection with the $150^{\text {th }}$ anniversary of the discovery by D. I. Mendeleev of the Periodic Law of Chemical Elements (1869). The article highlights the metrological activity of D. I. Mendeleev and tells about how in the scientific metrological center, he created the Main Chamber of Weights and Measures. Now the D.I. Mendeleyev Institute for Metrology (VNIIM) preserves the memory of the life and activities of the great Russian scientist and encyclopedist. Based on the research carried out in the archives of St. Petersburg and the funds of Metrological Museum, the article for the first time details the history of the formation of the Mendeleev memorial complex on the territory of VNIIM. The contribution of the institute metrologists to the creation of such famous sights of St. Petersburg as the monument to D. I. Mendeleev (sculptor I. Ya. Ginzburg, 1932) and the mural (mosaic) «D. I. Mendeleev Periodic system of elements» (1935) on the occasion of the $100^{\text {th }}$ anniversary of the scientist is shown. All peripteries, related to the installation of the monument - table are described: a selection of options for the arrangement of elements, decoration, manufacturer and manufacturing techniques, coordination with various organizations, solving financing issues.
\end{abstract}

Keywords: D. I. Mendeleev, D.I. Mendeleyev Institute for Metrology (VNIIM), Metrological Museum, monument to D. I. Mendeleev, mural (mosaic) D. I. Mendeleev's periodic system of elements.

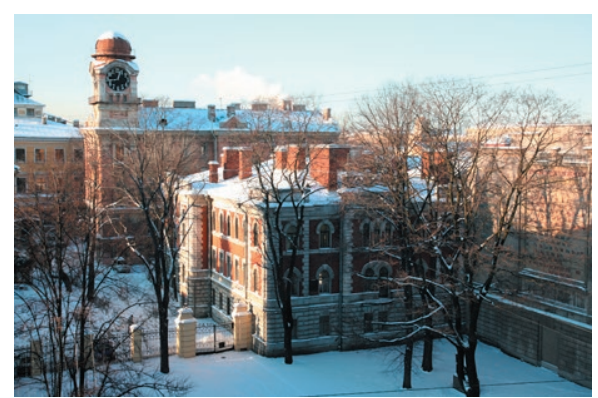

Figure 1. General view of the historic buildings of VNIIM, St. Petersburg, Russia, Moskovsky pr., 19. Photo from the collection of the Metrology Museum hosted by the D.I. Mendeleyev Institute for Metrology, November 2010. 
The year 2019 was notable for the two memorable dates associated with the name of D.I. Mendeleev, a great Russian scientist and encyclopedic mind of his time: February $8^{\text {th }}$ marked by the 185 th anniversary of the scientist's birth, and February $17^{\text {th }}$, the $150^{\text {th }}$ anniversary of the Periodic Law that he discovered. To honor these anniversaries, the United Nations General Assembly, in liaison with UNESCO, proclaimed 2019 the International Year of the Periodic Table of Chemical Elements, and the global scientific community widely celebrated these events. The year started with the opening ceremony at the UNESCO quarters in Paris on January 29, 2019 and the closing ceremony took place on December 5, 2019, in Japan.

In Russia, most of the anniversary events were held in St. Petersburg, the city that played the most important role in the life and work of D.I. Mendeleev. It was in this city indeed that he studied at the Chief Pedagogical Institute (Главный Педагогический Институт) (1855), discovered the famous Periodic Law of Chemical Elements (1869), and gave lectures for 40 years in the city's largest higher educational establishments, such as Institute of Railway Engineers, Technological Institute, St. Petersburg University (1861-1890). Then he founded and headed the first scientific metrological establishment of the country - Main Chamber of Weights and Measures (1892-1907) - which is still functioning today under the name of All-Russian Scientific Research Institute for Metrology and is known to the world as the D.I. Mendeleev Institute for Metrology (VNIIM). The scientist's name was appended to that of the Institute in 1945. The memory of the founder of

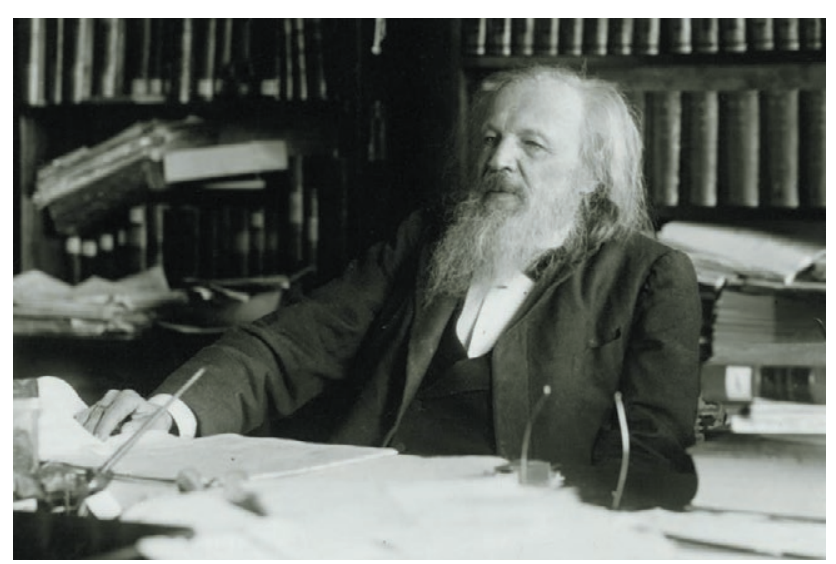

Figure 2. D. I. Mendeleev was the author and the main architect of the metrological reform in Russia (1892-1907). On his initiative, the Depot of Measures and Weights was transformed into a scientific metrological center - the Main Chamber of Measures and Weights (VNIIM since 1934). Photo from the collection of the Metrology Museum hosted by the D.I. Mendeleyev Institute for Metrology, 1904. scientific metrology has been held sacred at VNIIM for more than a century. ${ }^{1}$

The D.I. Mendeleev Institute for Metrology was instrumental in organizing and holding main Mendeleev-related events during the International Conference Mendeleev-150 and XXI Mendeleev Congress on General and Applied Chemistry. During the visits to VNIIM, Russian and foreign guests got acquainted with the Institute's activities and with the unique heritage connected to Mendeleev. The historical site and architectural objects located on its premises feature the century-old buildings where D.I. Mendeleev lived and worked, the sculptural and painted portraits of the scientist, and the Metrology Museum. Of particular interest is the Mosaic Panel displaying Mendeleev's Periodic System, produced on the initiative of metrologists in 1935 to be appended on the wall of the building adjacent to VNIIM (at that time this building belonged to the Artillery School, now housing the Suvorov Military School). The story behind the panel and a number of other monuments to D.I. Mendeleev on the VNIIM's territory is associated with the 100th anniversary of the scientist's birth celebrated in 1934 and is the topic of the present contribution.

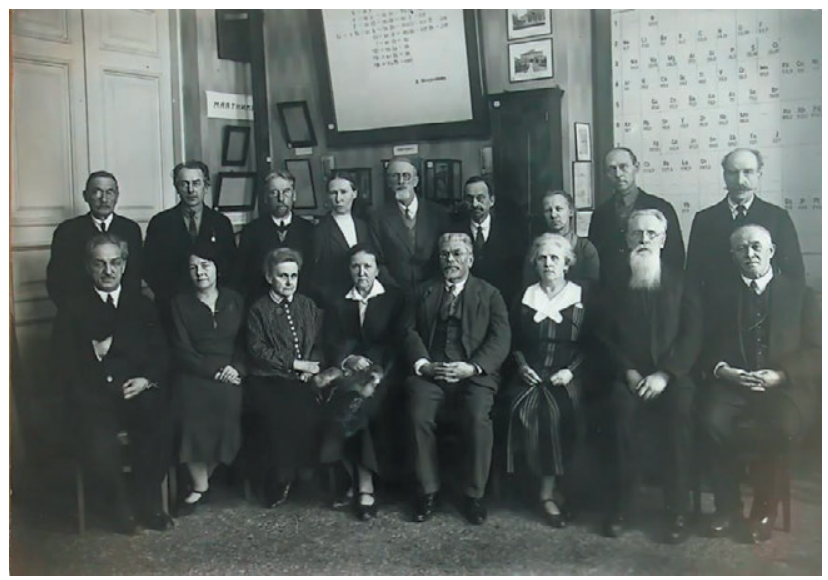

Figure 3. Employees of the Main Chamber of Measures and Weights, who worked with D. I. Mendeleev, posing in the first exhibit of the museum. Among them: Mikhail Mladentsev (former MCWM Scientific Secretary, sitting first from the left), Alexey Skvortsov (former personal secretary of D. I. Mendeleev, standing second from left), Alexander N. Dobrokhotov (standing third from left), Victor Mueller (standing fifth from left) and etc. Photo from the collection of the Metrology Museum hosted by the D.I. Mendeleyev Institute for Metrology, 1934. 


\section{HONORING THE MEMORY OF THE FOUNDER - CREATION OF THE MENDELEEV MUSEUM AND THE MONUMENT TO MENDELEEV IN THE MAIN CHAMBER OF WEIGHTS AND MEASURES}

Back in 1925, in order to preserve the memory of D.I. Mendeleev and his work, his colleagues and students founded Mendeleev Group at the Main Chamber of Weights and Measures (MCWM). It consisted of the MCWM President Dmitry P. Konovalov (Chairman), Mikhail N. Mladentsev, Alexander N. Dobrokhotov, Victor A. Mueller, Alexey.V. Skvortsov, as well as the scientist's son, Ivan D. Mendeleev. They formed the Mendeleev Fund of the Main Chamber Museum, which was opened to visitors on December 16, 1928, on the day of the Annual Grand Meeting of VNIIM staff. The first exhibit, located in the scientist's office, showcased not only D.I. Mendeleev's contribution to the development of metrology science, but also the main stages of his life and work. ${ }^{2}$

In 1930, the MCWM began preparations for the celebration for the 100th anniversary of Mendeleev's birth. To organize the celebration an All-Union Commission was created. Among its members there were the Director of the All-Union Research Institute of Metrology and Standardization (VIMS; former MCWM, today the D.I. Mendeleev Institute for Metrology, VNIIM), the academician M.A. Shatelen, the Heads of Republican Chambers of Weights and Measures, as well as Mikhail N. Mladentsev, who headed the Mendeleev Museum at the Main Chamber of Weights and Measures - VNIIM from 1928 to 1941.

On May 6, 1930, the Commission heard the report of M.A. Shatelen on the main activities planned by metrologists to prepare the celebration.

The main proposal was to "install a bronze monument to D.I. Mendeleev in the Main Chamber courtyard in front of the house where scientist lived". Previously, negotiations were held with the sculptor Ilya Ya. Gintzburg who "agreed to donate his beautiful work - a statue of D.I. Mendeleev sitting in his chair" and offered to cast and to install the monument, free of charge. According to D.I. Mendeleev's son and his widow, and to people who knew him well and worked closely with him, "the statue bears a great resemblance to Mendeleev".

Ilya Ya. Gintzburg made a statuette depicting a scientist sitting in an armchair with a book in 1890, then D. Mendeleev posed for the sculpture for three months (from March to April). I. Gintzburg took this work as a basis when creating a bronze monument to Mendeleev in the in the Main Chamber courtyard. (The author's copy of this figurine, made by Ilya Gintzburg of plaster, is still kept in the collection of the Metrological Museum).
Other proposals included publication of his works, making a film and a book on D.I. Mendeleev's metrological activity, drawing (and printing) his portrait, etc. ${ }^{3}$ The Commission decided to accept all those proposals submitted by M.A. Shatelen. ${ }^{4}$ They were accepted by the decision of the 9th All-Union Conference of Verification Specialists and sent to the Chairman of the Council of Labor and Defense (STO) Standardization Committee on December 9, 1930. As a result, the Resolution of the STO All-Union Committee for Standardization Presidium dated December 20,1930, decided to erect a monument dedicated to D.I. Mendeleev and to fund the corresponding work. ${ }^{5}$

Ilya Ya. Ginzburg redeemed his promises given to the Commission: he provided a model of the monument and supervised its casting and installation, all free of charge. The allocated funds were spent on materials granite and bronze.

It can be seen that the D.I. Mendeleev monument was created within a relatively short period of time. Its inauguration coincided with the 25th anniversary of

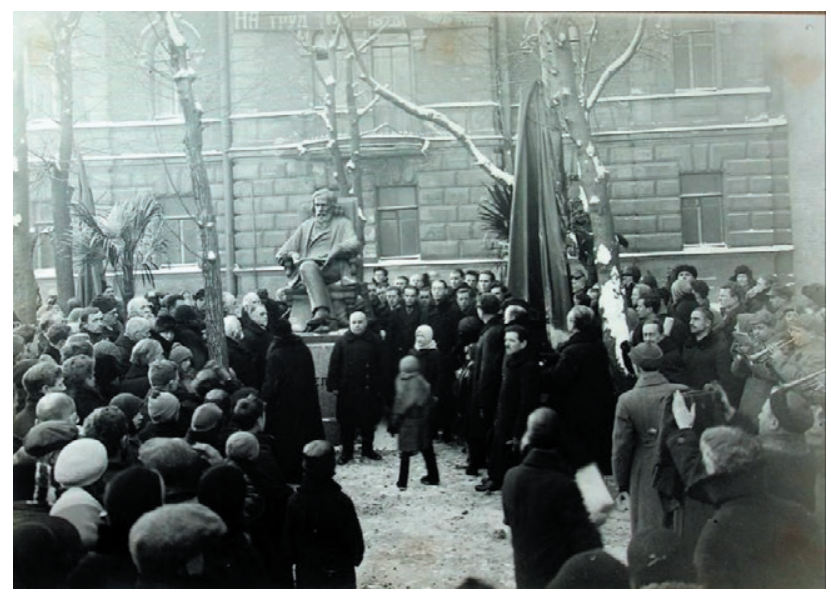

Figure 4. Inauguration of the monument to D. I. Mendeleev in the square of the Main Chamber of Measures and Weights. Photo of February 2, 1932 Photo from the collection of the Metrology Museum hosted by the D.I. Mendeleyev Institute for Metrology. Note. The figure (bronze, granite) is $1.86 \mathrm{~m}$, the pedestal of red unpolished granite is $1 \mathrm{~m}$. The monument is under protection of the State and it was included in the List of Historical and Cultural Heritage Objects of Federal Importance by the Decree of the Government of the Russian Federation No. 527 dated July 10, 2001). The monument is also registered with the State Budgetary Institution of Culture "State City Museum of Sculpture" (since 1993) and included in the Museum Fund of the Russian Federation (Preservation Order dated September 18, 2019, Order of the State Inspectorate for the Preservation of Monuments No. 07-19-439/18). B 1934 r. All-Union Scientific Research Institute of Metrology and Standardization (VIMS) was renamed into the All-Union Scientific Research Institute of Metrology (VNIIM). 
the scientist's death - February 2, 1932. The monument was placed in the MCWM courtyard on the very spot of the garden house favored by the scientist for taking a rest while living in the "Red House». D.I. Mendeleev is portrayed sitting on a chair with an open book in his hand surrounded by heavy volumes, manuscripts, and books, one bearing of them the inscription «Временник Главной палаты мер и весов» (Chronicles of the Main Chamber of Weights and Measures), which was the first metrological journal published in Russia on the initiative and under the leadership of D.I. Mendeleev. At the opening ceremony, academician M.A. Shatelen said: "I hope, this monument is a precursor. Probably, our State will build a worthy monument to honor Mendeleev's $100_{\text {th }}$ anniversary. But this small, one might say, homely monument, will be a place of pilgrimage for us, so to speak. Mendeleev is the founding father of our metrology. If we use extensive achievements of metrology, if we can legitimately consider our Institute, VIMS (All-Union Scientific Research Institute of Metrology and Standardization), to be one of the leading institutions of this kind on a global scale, we undoubtedly owe that to Dmitri Ivanovich». ${ }^{6}$

\section{CELEBRATING MENDELEEV THROUGH THE PERIODIC SYSTEM}

On September 22, 1933, to prepare for the $100^{\text {th }}$ anniversary of D.I. Mendeleev an Organizing Committee was created at VIMS for the "ceremonial honoring the memory of D.I. Mendeleev". It consisted of the Institute's staff: academician A.A. Baykov (Chairman), A.N. Dobrokhotov, S.Z. Snarsky (Director), profs. L.V. Zalutsky, M.F. Malikov, A.K. Kolosov, V.E. Murashkinsky, A.T. Gorbov, I.D. Mendeleev (son), and M.N. Mladentsev (Scientific Secretary).

The Committee was tasked with developing, approving, and supervising the list of events dedicated to the scientist's anniversary and the perpetuation of his memory, estimating the costs, liaising with other scientific institutions that wished to participate in the commemorative events. 7 Among the proposals received were among others: to rename the Mezshdunarodniy (International) Avenue into Mendeleev Avenue, to organize conferences, lecture courses, to republish D.I. Mendeleev works, to restore D.I. Mendeleev's estate in the village of Boblovo. The most interesting of the proposals received was to install a Mosaic Panel featuring Mendeleev's Periodic System of Elements on the wall of the Artillery School (today the Suvorov Military School) adjacent to VNIIM.

The making of the monument was discussed at the Organizing Committee meetings of 1933-1934, includ- ing the issues related to expenses, contracting, styling and manufacturing, as well as obtaining the necessary permits.

Negotiations were conducted with the Lomonosov Porcelain Factory, State Ceramic Research Institute and Russian Academy of Arts. Initially, it was planned to order the Table to be made of ceramic tiles at the Lomonosov Porcelain Factory art laboratory; however, during the negotiations held by Alexander K. Kolosov, it turned out that the monument would be ready only by the spring of 1934 (i.e. by the anniversary, but not by February 8). Yet still the most difficult was to decide which table should be used as a basis.

On December 27, 1933, the Organizing Committee discussed the proposal of A.I. Gorbov and M.N. Mladentsev, who were entrusted with drawing up a draft of the Table. They supported picturing the Table as it was printed in the $8^{\text {th }}(1906)$ edition of D.I. Mendeleev's Foundations of Chemistry. ${ }^{8}$ Some of the Committee members, including Ivan Dmitrievich Mendeleev, believed that "the Table would serve both as a monument, and a study guide, which would make it improper to depict the Table in 1934 as it was in 1906, because great changes have taken place since then". ${ }^{9}$

The discussion did not lead to a final decision, and VIMS Director S.Z. Snarskiy was charged with convening an ad-hoc meeting with academicians N.S. Kurnakov, A.B. Favorskiy, V.E. Tischenko, V.Ya. Kurbatov, S.P. Vukolov, I.Ya. Gintzburg, the representatives of the Lensovet Development Authority and VIMS public organizations to study drafts of the Table. ${ }^{10}$ Thus, by January of 1934, two main issues - which of the proposed Tables should be chosen and who should be commissioned to manufacture it - remained unresolved.

On January 15, 1934, given the newly discovered disagreements, an extended Organizing Committee meeting was held to discuss the drafts of the Table. After an extensive debate, the Committee decided to opt for the Periodic Table proposed by Ivan Mendeleev. The Table published in the $8^{\text {th }}$ edition of D.I. Mendeleev's Foundations of Chemistry was agreed upon as a basis, with addition of the elements discovered from 1906 to 1934. Protocol Resolution No. 11 states:

- to recognize, that all additions to the Table made after D.I. Mendeleev's death must be depicted in a different color,

- to recognize as desirable the addition of atomic weights to the Table, if no technical or esthetic considerations interfere with doing so,

- to ask the VIMS architect to prepare, according to instructions of A.K. Kolosov and I.D. Mendeleev, a draft of one or more symbols of the Table in full size 


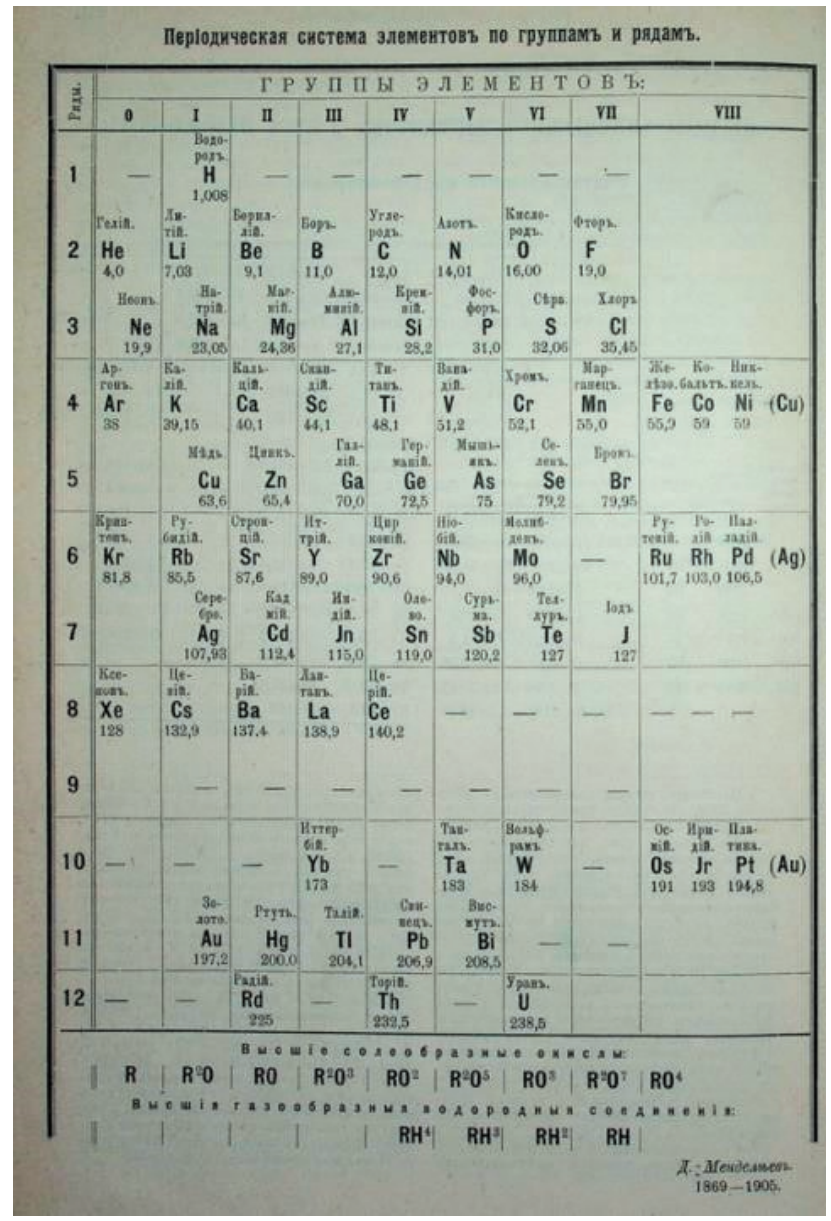

Figure 5. "Periodic System of the Elements» published in the book by D.I. Mendeleev "Fundamentals of Chemistry". St. Petersburg. 1906.

in two versions: with the elements only and with both the elements and their atomic weights. ${ }^{11}$

In January 1934, on behalf of the VIMS Director S.Z. Snarskiy, letters requesting installation of the Table were sent to the Head of the Artillery School and the Lensovet Development Authority, and the corresponding permits were obtained..$^{12}$ However, the issue of contractor still had not been decided upon. Even the option of making a temporary table using oil paints was contemplated, but that was declined because of the unfavorable climate conditions in the city.

Only on June 5, 1934, an agreement was concluded between VIMS, represented by its Director, S.Z. Snarskiy, and the All-Russian Academy of Arts, represented by the Head of Mosaic Department, Vladimir A. Frolov, on manufacturing of the Table. The Agreement states, that "The Institute instructs, and the Academy takes on execution of the memorial plate to Professor D.I. Men-

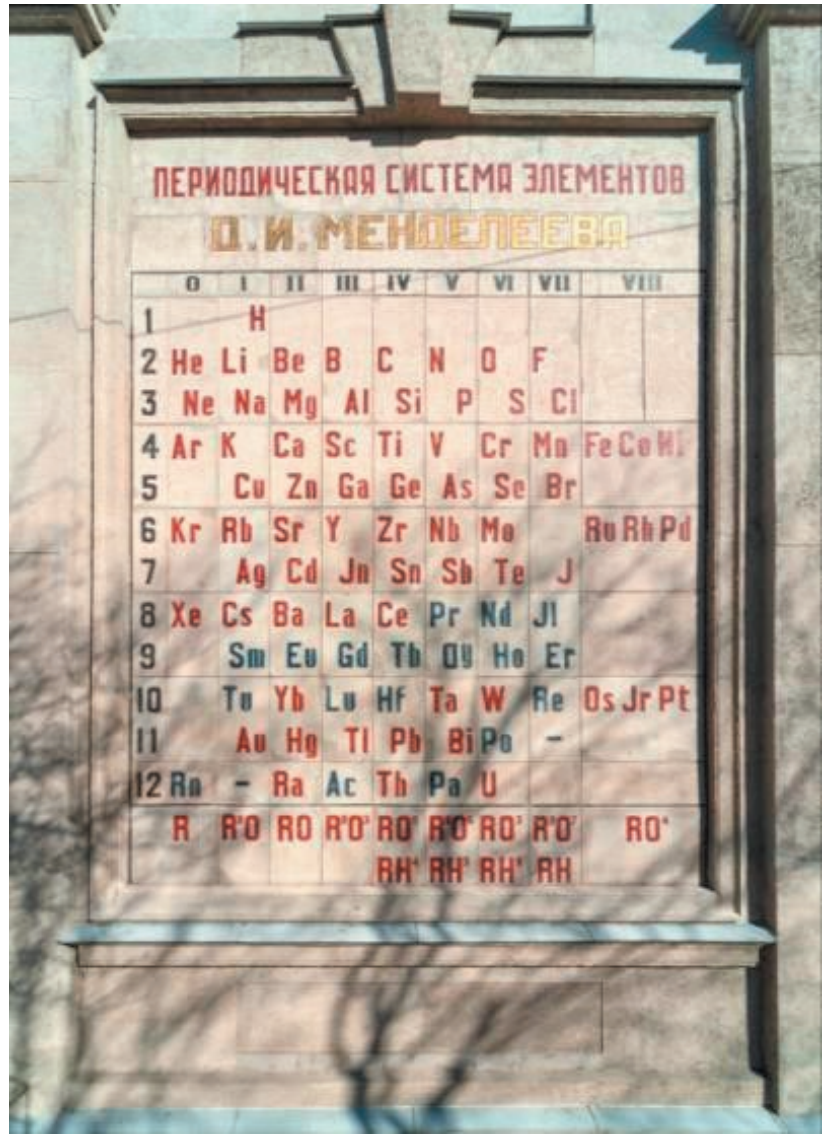

Figure 6. Mosaic panel «D.I. Mendeleev's Periodic System of the Elements». Photo taken by E.Ginak, 2019.

deleev with unpolished mosaics (letters and digits) on faux stone cement background with marble chips and with the same frame to place it on the side wall of the building adjacent to the Institute". ${ }^{13}$ The memorial plate was manufactured by the Academy using its materials; 12 barrels of Portland cement required for the project were provided by the Institute; the work was delivered in form of separate completed square stones of reinforced concrete without notching in two stages; the delivery of the finished parts was carried out by the Academy at its own expense. All work on installation of the tablet was carried out by the Academy; the Institute constructed the necessary scaffolding and provided 2 workers and cement mortar to fix the square stones on the wall. The Institute would pay the Academy 21000 rubles for the work. The deadline was October 15, 1934. ${ }^{14}$ All parts of the "memorial plate", as it was initially called, were manufactured and delivered on October 16, 1934, according to the Acceptance Certificate. ${ }^{15}$ Architectural design of the wall was developed by architect D.L. Krichevskiy. Inauguration of the Mosaic Panel with Mendeleev's 
Periodic System of Elements took place on November 10, 1935. (The height of the monument is $9 \mathrm{~m}$; the total area is 69 sq.m).

\section{LIFE OF A MONUMENT «D.I. MENDELEEV'S PERIODIC SYSTEM OF THE ELEMENTS»}

In 1983, during the preparation for the celebration of $150^{\text {th }}$ anniversary of D.I. Mendeleev, VNIIM pointed out that the Periodic System Mural needed some repairs. There were proposals to amend the state of the Table and to add the elements discovered after 1934. To this end, VNIIM applied to the authoritative commission (it included well-known historians of chemistry: professors Alexander A. Makarenya and Igor S. Dmiriev) asking it to check the accuracy of the Table symbols and structure. Finally, it was decided to act according to Protocol No. 11 dated January 15, 1934 and restore the monument to its original state.

In 2013-2017, a comprehensive reconstruction and restoration of the military school buildings was conducted. VNIIM sent a request to the State Inspectorate for the Preservation of Monuments to provide for the preservation and restoration of the unique mosaic on the wall. The Metrological Museum provided to the restorers the necessary information from archives on the history of the Periodic System Mural and on its particular features. A number of obvious repairs were carried out: cleaning, washing, reinforcement, etc. There are no plans now to introduce any changes to the 1935 Panel. Order No. 556-r dated 15.12.2017 of the State Inspectorate for Preservation of Monuments lists the "barracks" building and the Table

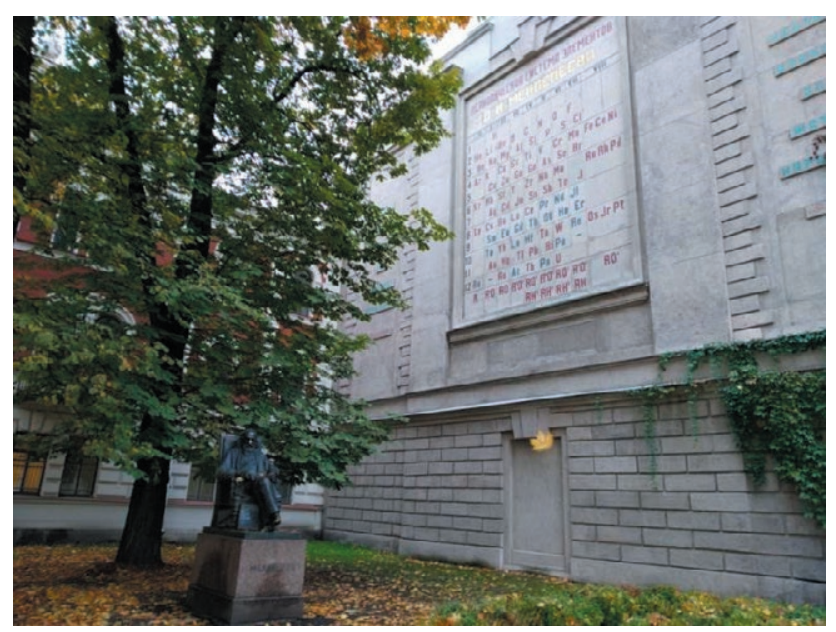

Figure 6. Monument to D.I. Mendeleev and Mosaic mural «D. I. Mendeleev Periodic System of Elements», St Peterbsurg. Photo taken by E.Ginak, 2019. on its wall in the register of cultural heritage objects of regional importance "Complex of buildings of the Imperial Orphanage (Konstantinovsky Military School)”.

\section{CONCLUSION}

Thus, thanks to the efforts of the staff of the Main Chamber of Weights and Measures (VNIIM), a unique memorial complex was created in 1932-1935 in the center of St. Petersburg, dedicated to Mendeleev and his famous discovery. It invariably attracts the attention of St. Petersburgers, Russian and foreign guests of the city.

\section{ACKNOWLEDGEMENT}

The author thanks the editors of the journal "Standards Reference Samples", where the article by E.B. Ginak was first published in Russian: https://www.rmjournal. ru/jour/article/view/218.

\section{REFERENCES}

1. Aleksandrov, V.S., Ginak, E.B. Participation of the D.I. Mendeleev Institute for Metrology in celebrations of the $175_{\text {th }}$ anniversary of D.I. Mendeleev. Izmeritelnaya tekhnika (Measuring technique). 2009. No. 6. Pp.70-72.

2. Ginak, E.B. Metrological Museum: history, collections, exhibitions, projects. Mir izmereniy (World of measurements). 2017. No. 2. P. 60.

3. Archive of the Metrology Museum hosted by the D.I. Mendeleyev Institute for Metrology (MM Archive). Оп.2. Д. 64. ЛЛ. 11, 11 об.

4. MМ Archive. Оп.2. Д. 64. Л. 12.

5. ММ Archive. Оп.2. Д. 64. Л.1.

6. ММ Archive. Оп. 2. Д. 58. Л. 33. + https://www. vniim.ru/news_107.html

7. MM Archive. Оп. 2. Д. 54. Л. 200.

8. ММ Archive. Оп.2. Д. 54. Л. 57 об.

9. MM Archive. Оп.2. Д. 54. Л. 54

10. ММ Archive. Оп.2. Д. 54. Л. 56

11. MМ Archive. Оп. 2. Д. 54. Л. 54-54 об.

12. MМ Archive. Оп. 2. Д. 54. ЛЛ. 183, 183 об.

13. Scientific archive of the Russian Academy of Arts (St. Petersburg). Ф. 7. Оп. 2. Д. 245. Л. 14.

14. Scientific archive of the Russian Academy of Arts (St. Petersburg). Ф. 7. Оп. 2. Д. 245. Л. 14 об.

15. Scientific archive of the Russian Academy of Arts (St. Petersburg). Ф. 7. Оп. 2. Д. 245. Л.22. 